\title{
A PRESENÇA DA FENOMENOLOGIA NA/DA TEORIA DO SE-MOVIMENTAR HUMANO (TSMH) BRASILEIRA ${ }^{1}$
}

\author{
Filipe Ferreira Ghidetti \\ Rede Municipal de Vitória, Vitória, Espírito Santo, Brasil \\ Felipe Quintão de Almeida \\ Universidade Federal do Espírito Santo, Vitória, Espírito Santo, Brasil \\ Valter Bracht \\ Universidade Federal do Espírito Santo, Vitória, Espírito Santo, Brasil
}

\begin{abstract}
Resumo
Discute a fundamentação da Teoria do "se-movimentar" humano (TSMH) na corrente filosófica da fenomenologia. Tem como objetivos: a) apresentar um quadro com as principais referências e conceitos fenomenológicos que aparecem na TSMH; b) analisar o uso que é feito da fenomenologia na TSMH quanto à fidelidade no trato dos conceitos. Se apóia na análise de textos de Elenor Kunz, autor responsável por sua divulgação/elaboração da TSMH no Brasil. Conclui que a principal referência fenomenológica da TSMH é a "Fenomenologia da Percepção" de Merleau-Ponty, e que os estudos fenomenológicos precisam ser aprofundados para viabilizar as possibilidades presentes na TSMH.

Palavras-chave: Movimento. Educação Física e Treinamento. Fenomenologia.
\end{abstract} Filosofia.

\section{Introdução}

\begin{abstract}
ASMH é uma perspectiva teórica desenvolvida no contexto holandês-alemão por autores como Jan W. I. Tamboer, Frederic Jacobus Johannes Buytendijk, Viktor von Weizsäcker, Paul Christian, Carl Christian Friedrich Gordijn e Andreas Heinrich Trebels. Trebels, talvez o principal nome da perspectiva na Alemanha, orientou o brasileiro Elenor Kunz em seu doutoramento, realizado na cidade de Hannover. A tese foi publicada no Brasil, em 1991, com o título: "Educação Física: ensino \& mudanças". Nesse livro, pela primeira vez aparecem as considerações de Kunz a respeito da TSMH. Desde en-
\end{abstract}

1- Essa pesquisa foi desenvolvida com o apoio financeiro da Coordenação de Aperfeiçoamento de Pessoal de Nível Superior (Capes). 
tão, este autor se destaca como o divulgador e principal expoente da perspectiva no País.

A TSMH é uma teoria que fornece uma conceituação sobre o corpo/movimento humano e estabelece parâmetros para que os professores compreendam as imagens que fazem de seus alunos ao analisá-los em movimento (em situação de aula). Ou seja, coloca-se potencialmente como possibilidade de fundamentação de uma teoria da EF.

Este artigo faz parte de uma pesquisa que tem como tema a TSMH. Nos nossos estudos, o objetivo geral foi, por meio de uma pesquisa teórica, analisar as condições de possibilidade de a TSMH fundamentar uma teoria pedagógica da Educação Física (EF) brasileira. Para atingir esse propósito, focamos nossas análises nos textos do próprio Kunz, embora tenhamos acessado, também, os textos de Trebels. No caso deste, nos concentramos nos três artigos de sua autoria (TREBELS, 1992, 2003, 2006), publicados em português, que tratam da temática. Em relação a Kunz, não há um conjunto de textos que tratam exclusivamente da TSMH. Por isso, recorremos a livros, textos publicados em revistas, congressos e capítulos de livro que tivessem sua autoria. Também selecionamos textos de co-autoria (ora com orientandos, ora em outros tipos de parceria), totalizando 18 produções.

Neste artigo, discutimos a presença de uma das principais influências teóricas da TSMH: a fenomenologia, em especial a desenvolvida por Merleau-Ponty. Portanto, no intuito de mapear o uso da fenomenologia que é utilizada na TSMH, compomos um cenário com: as referências bibliográficas relativas à fenomenologia; as categorias fenomenológicas mais frequentes na TSMH. Para apresentar o resultado dessa pesquisa teórica, organizamos o artigo em dois tópicos, seguido das considerações finais.

\section{As principais referências fenomenológicas na/da TSMH}

No intuito de estabelecer algumas chaves de leitura/interpretação do uso que é feito da fenomenologia na TSMH, procuramos, em primeiro lugar, salientar as principais referências, obras e/ou autores que mais aparecem. "Fenomenologia da Percepção", de Merleau-Ponty, foi referenciada em 15 dos 18 trabalhos analisados. Podemos destacar, ainda, o uso de dois dos holandeses que fazem parte das raízes da TSMH, como pudemos acompanhar em Trebels (2006): Jan W. I. Tamboer e Frederic Jacobus Johannes Buytendijk. Os textos "Mens- 
chenbilder hinter Bewegungsbilder" (As visões de homem subjacentes às visões de movimento), de 1985, "Philosophie der Bewegungswissenschaft" (Filosofia da ciência do movimento), de 1989, e "Sich-bewegen - ein Dialog zwischen Mensch und Welt" (Se-movimentar - um diálogo entre homem e mundo), de 1979, todos de J. Tamboer, foram bastante referenciados nos trabalhos analisados. $\mathrm{O}$ texto "Allgemeine Theorie der Menschlichen Haltung und Bewegung" (Teoria geral da conduta e do movimento humano, 1956), de Frederic Jacobus Johannes Buytendijk, foi referenciado em 7 (38\%) dos 18 artigos analisados. É necessário salientar a mínima presença, no trabalho de Kunz, de textos dos outros autores que estão, de acordo com Trebels (2006), presentes na raiz da TSMH: Viktor von Weizsäcker, Paul Christian e Carl Christian Friedrich Gordijn. Esses foram referenciados, principalmente, nos trabalhos de A. H. Trebels analisados. Se há uma base teórica da TSMH, como é anunciada em Trebels (2006), essa base não é trabalhada teoricamente na sua presença no Brasil (vale dizer, na obra de Kunz). Entendemos que uma barreira concreta, nesse sentido, é a questão da língua; afinal, estamos falando de textos escritos em holandês e em alemão. Sabemos também que, enquanto Buytendijk, Christian e Weizsäcker têm suas abordagens (sobre o movimento humano) ligadas a corrente da Gestaltkreis, Gordijn e Tamboer têm suas abordagens radicadas na fenomenologia francesa (principalmente Merleau-Ponty). Em outras palavras, os textos de Tamboer, em alemão, tiveram uma presença significativa nos trabalhos analisados e os textos desses outros quatro autores, também em alemão (menos os textos de Gordijn), não tiveram a mesma presença. Entendemos que essa centralidade de Tamboer nos textos de Kunz se deve ao lugar do holandês na TSMH. Tamboer foi aluno de Gordijn e é a partir dele que há uma espécie de síntese de uma Teoria do "se-movimentar" humano, com base na fenomenologia pontyana e localizada no contexto da EF (nesse caso, holandesa). Tamboer dá prosseguimento à "Concepção dialógica do movimento humano", elaborada por Gordijn.

Destaca-se a importância de Merleau-Ponty, e sua obra "Fenomenologia da Percepção", para a TSMH. Além de sua presença constante nas referências e no interior dos textos analisados, também encontramos essa informação em Trebels (2006): "Gordijn apóia-se, basicamente, nos pressupostos da Fenomenologia francesa, principalmente a de Merleau-Ponty (1966) e sua obra Fenomenologia da Percepção" 
(TREBELS, 2006, p. 38). Trebels (2006) ainda cita que Tamboer foi aluno de Gordijn e assumiu também a Fenomenologia francesa como a grande referência. Nas obras de Kunz, as outras referências relativas à Merleau-Ponty têm ocorrência baixa, e quase não há efetivo debate sobre o conteúdo das mesmas. Assim, podemos dizer que Kunz também se vale da "Fenomenologia da Percepção" como a grande referência pontyana da TSMH. A centralidade dessa obra na TSMH fica ainda mais evidente quando avaliamos em quantos dos trabalhos analisados aparecem conceitos fenomenológicos advindos dessa publicação, que data de 1945: 14/18 (77\%).

Sobre as principais referências bibliográficas da TSMH no Brasil, também é interessante identificar a recorrência dos seguintes autores: Edmund Husserl ${ }^{2}$, Andreas Heinrich Trebels e o próprio Elenor Kunz. A aparição de Kunz nas referências possivelmente se deve à necessidade do autor de retomar seus trabalhos antecedentes. Porém, ao mesmo tempo em que constatamos esse alto nível de referência aos seus textos (12 dos 18 trabalhos, o que corresponde a 66,6\%), o índice de aproveitamento dos conceitos fenomenológicos é baixo - apenas 4 dos $18(22,2 \%)$ trabalhos se incluem nessa lista. Isso demonstra um indício de pouco trabalho teórico de apresentação dos preceitos fenomenológicos na produção de Kunz. Trebels é também referenciado em 12 dos 18 trabalhos, porém, com a diferença de que em todas as vezes que foi referenciado manifestou-se também o aproveitamento de conceitos fenomenológicos. Queremos dizer que houve, neste caso, citação e apropriação das descrições feitas por Trebels, de conceitos fenomenológicos. Isso endossa a grande importância de Trebels na teoria, principalmente no texto "A concepção dialógica do movimento humano: uma teoria do "se-movimentar", de 2006 - que, para nós, constitui uma espécie de síntese da TSMH. Quanto à Husserl, registramos quatro de suas obras nas referências dos trabalhos analisados. "Meditações cartesianas" apareceu em 4 trabalhos e teve seus conceitos fenomenológicos aproveitados nesses 4 trabalhos. Se podemos dizer que as referências husserlianas aparecem em poucos trabalhos da TSMH, o mesmo não se pode dizer do aproveitamento dos conceitos fenomenológicos dessas obras: quase sempre que uma das obras de Husserl

2-Edmund Husserl é um filósofo alemão que viveu nos séculos XIX e XX, e foi o precursor do movimento fenomenológico. Depois dele, essa corrente teórica se expandiu por caminhos que o próprio Husserl não previra. 
aparece nas referências, os conceitos fenomenológicos dessa obra são utilizados.

Ainda sobre as principais referências e autores, averiguamos as contribuições dos "comentadores" e da comunidade da EF na fundamentação fenomenológica da TSMH. A partir das listagens das principais obras e principais autores, podemos ver que o uso de comentadores na TSMH é baixo. No total, 11 dos 18 trabalhos analisados não se utilizaram dos recursos dos "comentadores" (apenas 7 trabalhos se utilizaram desse recurso). Quer dizer, não se recorre aos comentadores de Merleau-Ponty para se explicar alguns dos seus conceitos. No que se refere à contribuição da comunidade da EF brasileira na fundamentação fenomenológica da TSMH, o uso é ainda menor.

Em resumo, não há uma genealogia dos conceitos fenomenológicos dentro da TSMH. Com isso, queremos dizer que dificilmente encontramos manifestações sobre as raízes dos conceitos abordados. Entendemos que, além de citar de onde vêm os conceitos, há a necessidade de explicitar como esses conceitos se sustentam face ao problema motivador do estudo.

$\mathrm{Na}$ sequência elencamos os principais conceitos e/ou ideias fenomenológicas que aparecem na TSMH e discutimos como esses conceitos se configuram na fenomenologia de Maurice Merleau-Ponty.

\section{Os principais conceitos e/ou ideias fenomenológicas na TSMH}

Existe um grupo de conceitos ou ideias que se repetem e compõem o quadro da TSMH no Brasil. "Crítica à ciência e à mecanização do mundo a partir da dicotomia sujeito-objeto" aparece em 12 trabalhos; "Unidade primordial homem-mundo" (relação homem-mundo) aparece em 14; "Intencionalidade" aparece em 12; "Se-Movimentar" (Concepção dialógica do movimento humano) aparece em 17; "Sentido/significado" aparece em 15 trabalhos; "Mundo vivido" (Lebenswelt) aparece em 8; "Mútua condicionalidade entre movimento e percepção" aparece em 8. Mais do que uma seleção pela quantificação, essa é uma seleção "qualitativa". Muitos dos conceitos ou ideias restantes são complementares à essas que elencamos, como, por exemplo, "Movimento concreto" e "Movimento abstrato" em relação à "Se-Movimentar". Segue um esquema dos principais ideias e conceitos fenomenológicos identificados: 


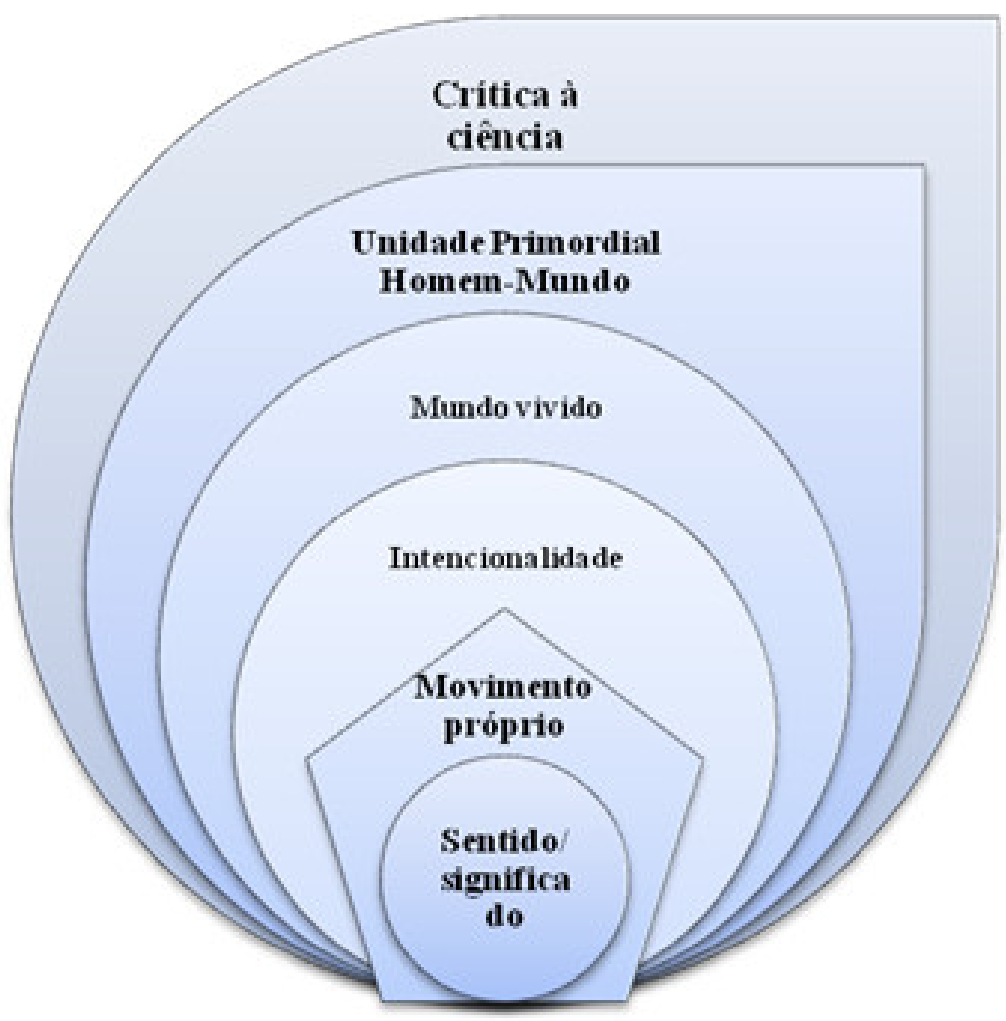

Esquema 1: Conceitos fenomenológicos presentes na TSMH

No que diz respeito à ideia de "Crítica à Ciência e à mecanização do mundo a partir da dicotomia sujeito-objeto", ela engloba outras nomeações que expressam o mesmo sentido pretendido. MerleauPonty costumava dizer que a fenomenologia de Husserl é, antes de qualquer outra coisa, uma crítica às ciências (MERLEAU-PONTY, 1999). Uma crítica ao ideal cartesiano de projetar um mundo de certezas a partir da certeza da consciência. Não podemos dizer que se trata de um conceito fenomenológico, seja de Merleau-Ponty ou de Husserl, mas de um ponto de partida, um pano de fundo para as teorizações fenomenológicas (daí a denominarmos de ideia) ${ }^{3}$. Em Husserl, essa crítica toma a forma de um "resgate da verdadeira filosofia" pela crise da cultura pela qual passava no seu tempo (KUNZ, 2000). Segundo Kunz (2000, p. 3),

Logo, os primeiros escritos de Husserl já eram dominados por uma crítica às ciências formais que se interessavam unicamente

3-Essas ideias, claro, se baseiam em conceitos (às vezes em mais de um). 
pela busca de conhecimentos objetivos transformados em leis pela experimentação comprovada de sua verdade.

É justamente a partir dessa crítica que Husserl inscreve a sua fenomenologia, com o ideal de "voltar às coisas mesmas". A crítica feita por Merleau-Ponty procura focar o caráter reducionista do conhecimento científico, segundo a qual também é preciso "retornar às coisas mesmas" devido ao caráter secundário que tem o conhecimento científico em relação ao conhecimento da experiência. É esse mundo anterior ao conhecimento que é foco de Merleau-Ponty em "Fenomenologia da Percepção", e é em relação ao mesmo que o conhecimento científico é abstrato, significativo e dependente. "Retornar às coisas mesmas é retornar a este mundo anterior ao conhecimento do qual o conhecimento sempre fala, "[...] como a geografia em relação à paisagem - primeiramente nós aprendemos o que é uma floresta, um prado ou um riacho" (MERLEAU-PONTY, 1999, p. 4). Nesse sentido, é preciso fazer falar o mundo porque a ciência fala das coisas e se recusa a habitá-las. O principal foco da crítica pontyana é o dualismo cartesiano que separa a mente do corpo e deixa como alternativa o empirismo, o idealismo, o intelectualismo ou o realismo. Esse é o ponto de partida da fenomenologia que deve ser considerado e que está presente na TSMH. Segundo a interpretação de Loturco (2010, p. 89),

Merleau-Ponty nos propõe uma interrogação filosófica como recomeço radical que implica o abandono dos dualismos cartesianos que, segundo Chauí (2002, p.160), impediu 'um pensamento ancorado na união entre a alma e o corpo e na relação originária do sujeito e do mundo'. Trata-se, pois, de romper com 'os erros gêmeos e rivais do idealismo e do realismo, do intelectualismo e do empirismo, passando a interrogar os fenômenos e a experiência depois de haver renunciado à ficção da reflexão como coincidência entre pensar e ser' (Chauí 2002, p.160), ou seja, rejeitar toda essa herança filosófica deixada pelo cartesianismo (LOTURCO, 2010, p. 89).

A "Crítica à ciência e à mecanização do mundo a partir da dicotomia sujeito-objeto" é pano de fundo para quase todos os textos que discutem como o movimento humano deve ser compreendido. Essa 
crítica toma, na TSMH, uma configuração de crítica ao paradigma empírico-analítico na análise do movimento humano. Segundo o que encontramos na TSMH, o paradigma empírico-analítico reduz a experiência de contato original com o mundo que, é o movimento humano, a uma relação de causa-efeito.

A "Unidade primordial homem-mundo" constitui uma ideia que procura clarificar a unidade existente entre homem e mundo, corpo e alma. Trata-se de um conceito que aparece somente na obra de 1945 de Merleau-Ponty. Na TSMH de Kunz, representa uma forma de comunicação (e constituição imediata de sentidos) com o mundo. Tendo em vista que o se-movimentar é uma atualização da unidade primordial homem-mundo, como vimos em Kunz (1998), segue-se que o “[...] se-movimentar é a forma de um agir original do ser humano, por meio da qual ele se garante como ser-no-mundo e na qual - neste agir - ele mesmo, como sujeito, e o mundo, como sua contraface imaginária, adquirem contornos visíveis" (TREBELS, 2006, p. 40). Com essa ideia, Merleau-Ponty combate principalmente o ideal ontológico do objetivismo que prevê a organização partes extra partes do Ser. O objetivismo sustenta a organização substancial do mundo que é explicada pela relação objetiva (independente) e exterior entre as partes que, por sua vez, compõem o Ser. Isso transforma até os processos da consciência em fatos, em efeitos. Merleau-Ponty procura, assim, problematizar a concepção da percepção como uma operação física, uma operação estrita dos sentidos no modo de captação de dados que serão codificados internamente. É isso que procura demonstrar em "Fenomenologia da Percepção" com o caso do "membro fantasma", em que os pacientes amputados continuam a "sentir" os membros mesmo depois da operação (MERLEAU PONTY, 1999).

A "Unidade primordial homem-mundo" é a ideia de MerleauPonty que abre espaço para outra forma de compreensão do movimento e consolida uma base para todas as outras categorias que elencamos. Todas elas ajudam a compreender o movimento humano como algo que vai além de um simples deslocamento no tempo e no espaço físico (concepção mecânica de movimento).

A categoria "Mundo vivido" (Lebenswelt) tem origem em Husserl e procura designar a experiência humana pré-conceitual. Para Merleau-Ponty, o corpo é a base dessas experiências do mundo vivido. Por meio da percepção, são fornecidos dados que precedem o pensamento. 
Assim, o mundo vivido é transformado pelo corpo em um mundo de possibilidades. Para Kunz et al. (2007, p. 49),

Segundo Thiele (1990), Husserl caracteriza o Lebenswelt como um 'estilo global' que diferencia as pessoas no cotidiano de mundos especiais ou do próprio ambiente em que vivem; o 'Lebenswelt' representa, assim, a 'redução' fenomenológica do mundo cotidiano e, ao mesmo, tempo, um horizonte não-tematizado de todo indivíduo.

$\mathrm{Na}$ "Fenomenologia da Percepção" é o mundo acessível à percepção que a ciência ignora como simples aparência. Esse mundo

[...] parece-nos, à primeira vista o que melhor conhecemos, já que não são necessários instrumentos nem cálculos para ter acesso a ele e, aparentemente, basta-nos abrir os olhos e nos deixarmos viver para nele penetrar. Contudo, isso não passa de uma falsa aparência. [...] esse mundo é ignorado por nós enquanto permanecemos numa postura prática ou utilitária, que foram necessários muito tempo, esforços e cultura para desnudá-lo e que um dos méritos da arte e do pensamento modernos [...] é o de fazer-nos redescobrir esse mundo em que vivemos mas que somos sempre tentados a esquecer (MERLEAUPONTY, 2004, p. 1-2).

Para Merleau-Ponty, o mundo vivido é um horizonte aberto ao indivíduo, como que uma fresta no Ser, o "[...] estilo universal de toda percepção possível" (DUPOND, 2010, p. 54). A apresentação do mundo como horizonte se comprova, principalmente, no prolongamento indefinido da percepção do objeto e é esse movimento ambíguo de doação e retração que provém a realidade do objeto. "Ora, é a orientação em direção a um só pólo, o mundo, que não permite mais a distinção entre as ordens do em si e do para si. Elas foram reintegradas à existência" (CARDIM, 2007, p. 30). Há ainda dois aspectos que caracterizam o sentido do ser do mundo em Merleau-Ponty: a) a facticidade do mundo, algo que não se pode dar inteiramente a razão, como diz o autor; e b) a individualidade, que coloca o mundo como um indivíduo que se autoafirma, que tudo abarca. No contexto da TSMH, o conceito de "Mundo vivido" procura caracterizar as experiências 
cotidianas de crianças em espaços fora da escola, que devem servir de base para a intervenção da EF. Kunz (2004) busca em Maraun (1981) uma definição para "Mundo vivido": trata-se do "[...] contexto social onde as condições objetivas tornam-se subjetivamente significativas" (MARAUN, 1981 apud KUNZ, 2004, p. 86). Assim, refere-se principalmente ao que os sujeitos em questão já mobilizam em relação às experiências de movimento.

Na TSMH (e também na "Fenomenologia da Percepção") é justamente o contato imediato do sujeito com o mundo que permite a produção de sentido. O sentido, nesse caso, não é atributo nem do homem e nem do mundo, mas surge da relação. Na tentativa de superar as armadilhas do empirismo e do intelectualismo, Merleau-Ponty elabora estruturas que preveem uma nova organização para a gênese do sentido. A primeira estrutura é a da "Intencionalidade", outra das categorias presentes na fenomenologia:

[...] Merleau-Ponty também fala daquilo que gira em torno de conexões funcionais entre os organismos e o seu meio ambiente, a saber, a intencionalidade. A ela corresponde o princípio básico de Husserl de uma intencionalidade 'atuante', que não é uma intencionalidade de atos conscientes, mas sim que fundamenta uma 'unidade natural, ante-predicativa do homem e do mundo' (MP 1966, pg. 15). Tendo em vista que Merleau-Ponty estende o âmbito do intencional ao agir motor, afetivo e sexual, o processo de constituição de sentido pode também ter lugar na espontaneidade corporal e substituir o 'eu penso' cartesiano pelo 'eu posso' originário (ibid., pg. 166). A concepção de uma intencionalidade fundada no corpo e perceptiva torna possível a Merleau-Ponty estabelecer um contínuo genealógico entre a organização física da percepção e sua interpretação simbólica e cultural [...] (ÉDEN, 1993, p. 123-126).

Podemos dizer, também, que esse é um ponto que estabelece um contínuo entre o psicológico e o fisiológico. Kunz et al. (2007, p. 41) comentam que a consciência está enraizada no corpo na fenomenologia pontyana: "o princípio da intencionalidade [...] indica um movimento de exteriorização da consciência em direção aos objetos”. Só há sentido encarnado em um corpo. O corpo é o marco zero da expressão e o exprimido existe no próprio ato da expressão e apenas nele. $\mathrm{O}$ sen- 
tido, ainda que pré-objetivo, é atributo do corpo enraizado no mundo, do ser-no-mundo. E essa capacidade

[...] passa do corpo humano para os outros corpos por contiguidade ontológica: nosso corpo faz os significados existirem como coisas e as coisas como significados: "essa revelação de um sentido imanente ou nascente no corpo vivo estende-se [...] a todo o mundo sensível, e nosso olhar, instruído pela experiência do corpo próprio, reencontrará em todos os outros 'objetos' o milagre da expressão" (PP 230). Vê-se, pois, que em 1945 a expressão depende de uma estrutura metafísica do corpo humano que é uma potência aberta e indefinida de significar. A partir do artigo sobre "A linguagem indireta e as vozes do silêncio" (1952), o problema da expressão se afasta da estrutura metafísica do corpo e, sob a influência da linguística, passa para a jurisdição da estrutura diacrítica da significação (DUPOND, 2010, p. 29).

Em Kunz et al. (2007) encontramos, pela primeira vez uma pista da raiz fenomenológica do conceito de se-movimentar, que é central na TSMH. No artigo citado, os autores sinalizam que o se-movimentar está relacionado à ideia de "movimento próprio" (Sich Bewegen) de Merleau-Ponty. O movimento é o que atesta a verdadeira unidade entre sujeito-objeto, é o que transcende o corpo da condição de corpo objetivo. O que queremos dizer é que, a partir do corpo, há uma primeira relação de sentido com o mundo, por meio do movimento próprio. Para Merleau-Ponty, o movimento próprio é o dispositivo que habilita a pensar a "Unidade primordial homem-mundo" porque o movimento é o que, mutuamente condicionado pela percepção, caracteriza a abertura do mundo não mais como pura interioridade e nem como pura exterioridade. Aqui, o corpo tem grande ênfase na caracterização de movimento próprio porque é a estrutura de onde provém o sentido. Em "Fenomenologia da Percepção", assim se configura o conceito de movimento próprio:

Se o espaço corporal e o espaço exterior formam um sistema prático, o primeiro sendo o fundo sobre o qual pode destacar-se ou o vazio diante do qual o objeto pode aparecer como meta de nossa ação, é evidentemente na ação que a espacialidade do 
corpo se realiza, e a análise do movimento próprio deve levarnos a compreendê-la melhor. Considerando o corpo em movimento, vê-se melhor como ele habita o espaço (e também o tempo), porque o movimento não se contenta em submeter-se ao espaço e ao tempo, ele os assume ativamente, retoma-os em sua significação original, que se esvai na banalidade das situações adquiridas (MERLEAU-PONTY, 1999, p. 149, grifo nosso).

Em "Fenomenologia da Percepção", a mútua relação entre movimento e percepção é dependente de uma intencionalidade, e então, estrutura-se a relação de significação no contato do homem com o mundo. Nos dizeres de Trebels (2006, p. 25),

Certamente a constituição intencional de uma pessoa é decisiva para, por exemplo, ela querer movimentar-se para um determinado ponto e conseguir reajustar sua percepção com o passar do tempo.

Esse é o ponto da "Fenomenologia da Percepção" que caracteriza o corpo como uma potência metafísica de significação. Vejamos o que Nóbrega (2011, p. 132, grifo nosso) diz a esse respeito:

Nessa crítica a uma visão mecanicista do corpo, destacam-se noções importantes, tais como a noção de corpo-próprio e a noção de motricidade. A noção de corpo-próprio envolve as relações entre ter e ser corpo. Não estou diante do meu corpo, sou meu corpo. Merleau-Ponty (1945), assim como fizera Nietzsche anteriormente, afirma uma ontologia do corpo, uma afirmação do sujeito não pelo cogito, razão ou consciência, mas pela sua condição corpórea. A ontologia do corpo apresentada por Merleau-Ponty irá se afastar das noções de sujeito ou de consciência, tomando como referência a percepção dos movimentos do corpo. Nesse contexto, a noção de motricidade refere-se à intencionalidade do movimento e do gesto, no sentido de moverse no mundo, criar horizontes, alargar a experiência vivida, em direção aos projetos, à expressão, à sexualidade. Não se trata de uma intencionalidade de juízos, raciocínios lógicos, mas de uma cinestesia possível pela nossa condição corpórea. Essas noções 
irão alargar a materialidade biológica e contribuir para problematizar os determinismos científicos faces à experiência do corpo vivo. Merleau-Ponty ultrapassa o determinismo biológico, a visão naturalista ou inata para tratar do corpo, do seu movimento, dos seus afetos.

É no "sou meu corpo" que não há um afastamento radical das noções de sujeito e de consciência, como na citação acima (pelo menos na obra de 1945). O movimento próprio é, portanto, o que possibilita ao corpo a relação de sentido com o mundo, sendo, como afirmarmos, fundamental para o sujeito que se movimenta.

\section{Considerações finais}

Neste artigo, discutimos a presença do referencial fenomenológico na/da TSMH. Tomamos como "fonte" os textos do autor que, no Brasil, foi pioneiro ao introduzir e trabalhar na consolidação dessa perspectiva teórica. Na análise oferecida, não colocamos em questão os méritos de Kunz nessa empreitada. Ao contrário, reconhecemos que sem seu esforço essa teoria não teria alcançado a importância que desfruta no campo da EF brasileira. Nosso exercício consistiu em uma tarefa de caráter mais técnico, interessada em, inicialmente, discriminar as referências bibliográficas relativas à fenomenologia presente em cada um dos trabalhos que vieram a compor a nossa caracterização da TSMH. Com essa estratégia, traçamos um panorama dos autores e obras que são citados. Identificamos, com isso, a "fenomenologia" que se pode encontrar na TSMH. Após esse exercício, explicamos algumas categorias fenomenológicas mais utilizadas nos textos de Kunz. Esse exercício permitiu-nos identificar o uso da fenomenologia na TSMH.

A investigação também demonstrou que a presença da fenomenologia na TSMH que conhecemos no Brasil tem em Merleau-Ponty sua principal referência e que "Fenomenologia da Percepção" é a obra mais utilizada no âmbito da TSMH. Na medida em que se baseia exclusivamente na "Fenomenologia da percepção", desconsidera-se que Merleau-Ponty produziu revisões em sua obra que afetam, inclusive, algumas ideias contidas no livro de 1945. Não significa que outros autores, como Husserl, não sejam mencionados ou, então, que outros livros de Merleau-Ponty não sejam citados, mas essa não é a regra. 
Além disso, indica que outros autores do contexto europeu (HolandaAlemanha), importantes à TSMH, são praticamente desconhecidos no Brasil (talvez por conta do problema do idioma), o que torna a presença da TSMH no País quase que exclusivamente atrelada à fenomenologia (da percepção). A discussão detalhada desses aspectos extrapola os limites desse texto e merecem atenção especial em novas pesquisas.

\title{
THE PRESENCE OF PHENOMENOLOGY IN/OF THE BRAZILIAN VER- SION OF THE HUMAN MOVEMENT THEORY (HMT)
}

\begin{abstract}
This paper discusses the foundations of the Human Movement Theory (HMT) in the philosophical movement of Phenomenology. The paper aims at: a) presenting a framework with the main phenomenological references and concepts that are present in the HMT; b) analyzing the use of Phenomenology in the HMT concerning the reliability in dealing with phenomenological concepts. The study is based on the analysis of texts by Elenor Kunz, author responsible for the dissemination / development of the HMT in Brasil. It is concluded that the main phenomenological reference of the HMT is the "Phenomenology of Perception", by Merleau-Ponty, and that the phenomenological studies need to be further developed to enable the possibilities of the HMT.

Keywords: Movement. Physical Education and Training. Phenomenology. Philosophy.

\section{LA PRESENCIA DE LA FENOMENOLOGÍA EN LA / DE LA TEORÍA DEL MOVERSE HUMANO (TSMH) BRASILEÑA}

\section{Resumen}

Discute la fundamentación de la Teoría del "moverse" humano (TSMH) en la corriente filosófica de la fenomenología. El artículo tuvo los siguientes objetivos: a) presentar un cuadro con las principales referencias fenomenológicas y conceptos fenomenológicos que aparecen en la TSMH; b) analizar cómo es usada la fenomenología en la TSMH en relación a la fidelidad en el tratamiento de los conceptos fenomenológicos. Se apoya en el análisis de textos de Elenor Kunz, autor responsable por la divulgación/elaboración de la TSMH en Brasil. Se concluye que la principal referencia fenomenológica de la TSMH es la "Fenomenología de la Percepción" de Merleau-Ponty, y que los estudios fenomenológicos necesitan profundizarse para la viabilidad de las posibilidades presentes en la TSMH.

Palabras clave: Movimiento. Educación y Entrenamiento Físico. Fenomenología. Filosofía. 


\section{Referências}

CARDIM, L. A ambiguidade na Fenomenologia da Percepção de Maurice Merleau-Ponty. 2007. 199 f. Tese (Doutorado em Filosofia) - Programa de Pós-Graduação do Departamento de Filosofia da Faculdade de Filosofia, Letras e Ciências Humanas da Universidade de São Paulo, São Paulo, 2007.

DUPOND, P. Vocabulário de Merleau-Ponty. São Paulo: Martins Fontes, 2010.

ÉDEN, T. Percepção e Linguagem em Merleau-Ponty e Wittgenstein. In: CASATI, G. et al. (Ed.). Philosophie und die cognitiven Wissenschaften. Kirchberg: Österreichischen Ludwig Wittgenstein Gesellschaft, 1993. p. 123-126.

KUNZ, E. Educação Física: Ensino \& mudanças. Ijuí: Unijui, 2004.

. Limitações no fazer ciência em educação física e esportes: CBCE, 20 anos auxiliando na superação. Revista Brasileira de Ciências do Esporte, Campinas, p. 4-11, set., 1998. Número especial.

. Esporte: uma abordagem com a fenomenologia. Movimento, Porto Alegre, v. 6, n. 12, p. 1-13, 2000.

. Ciências do Esporte, da Educação Física e do movimento humano: prioridades, privilégios e perspectivas. In: CARVALHO, Y.; LINHALES, M. (Orgs.). Política Científica e Produção do Conhecimento em Educação Física. Goiânia: Universidade Federal de Goiás, 2007. p. 87-106.

KUNZ, E. et al. Por uma didática da possibilidade: implicações da fenomenologia de Merleau-Ponty para a Educação Física. Revista Brasileira de Ciências do Esporte, Campinas, v. 28, n. 2, p. 39-53, jan., 2007.

KUNZ, E. et al. A dança como movimento humano significativo. In: CONGRESSO BRASILEIRO DE CIÊNCIAS DO ESPORTE, 17., 2011, Porto Alegre; CONGRESSO INTERNACIONAL DE CIÊNCIAS DO ESPORTE, 4., 2011, Porto Alegre. Anais... Porto Alegre: [s. n.], 2011. Disponível em: $<$ http://www.rbceonline.org.br/congres- 
sos/index.php/XVII_CONBRACE/2011/index>. Acesso em 16 nov. 2011.

KUNZ, E; SURDI, A. G. A fenomenologia como fundamentação para o movimento humano significativo. Movimento, Porto Alegre, v. 15, n. 2, p. 187-210, abr./jun., 2009.

LOTURCO, V. Merleau-Ponty dialoga com o racionalismo e a pintura em "O olho e o espírito". Cadernos Espinosanos, São Paulo, n. 22, p. 85-140, jan./jun., 2010.

MERLEAU-PONTY, M. Fenomenologia da percepção. São Paulo: Martins Fontes, 1999.

. Conversas. São Paulo: Martins Fontes, 2004.

NÓBREGA, T. P. Merleau-Ponty: movimentos do corpo e do pensamento. Revista Vivência, Natal, n. 36, p. 127-136, 2011.

TREBELS, A. H. Plaidoyer para um diálogo entre teorias do movimento humano e teorias do movimento no esporte. Revista Brasileira de Ciências do Esporte, Campinas, v. 13, n. 3, p. 338-344, maio, 1992.

TREBELS, A. H. Uma concepção dialógica e uma teoria do movimento humano. Perspectiva, Florianópolis, v. 21, n. 1, p. 249-267, jan./jun., 2003.

TREBELS, A. H. A concepção dialógica do movimento humano uma teoria do "se-movimentar". In: KUNZ, E.; TREBELS, A. H. (Orgs.). Educação física crítico-emancipatória: com uma perspectiva da pedagogia alemã do esporte. Ijuí: Unijuí, 2006. p. 27-48.

Recebido em: 03/08/2012

Revisado em: 14/12/2012

Aprovado em: 09/03/2013

Endereço para correspondência

fqalmeida@hotmail.com

Felipe Quintão de Almeida

Universidade Federal do Espírito Santo, Centro de Educação Física e Desportos. 
DOI 10.5216/rpp.v16i3.19554

Av. Fernando Ferrari, n. 514. Departamento de Ginástica, Goiabeiras 29075-910 - Vitoria, ES - Brasil 